\title{
Black sea urchins evaluate predation risk using chemical signals from a predator and injured con- and heterospecific prey
}

\author{
Vanessa Rímoli Morishita, Rodrigo Egydio Barreto* \\ Departamento de Fisiologia, Instituto de Biociências, Caunesp, UNESP, Rubião Jr. s/n, 18618-970, Botucatu, São Paulo, Brazil
}

\begin{abstract}
The traits related to foraging and eating are crucial to our understanding of food webs. The use of signals to detect predators has strong relevance for prey survival. The black sea urchin Echinometra lucunter cohabits with the green sea urchin Lytechinus variegatus and a generalist echinivorous predator, the cushion sea star Oreaster reticulatus. Because black sea urchins evolved under the same predation pressure as green sea urchins and, consequently, were exposed to the same sensory cues, they are hypothesised to be able to detect echinivorous predator odours and chemical cues from green sea urchins as well as from injured conspecifics to elicit antipredator responses. Black sea urchins responded strongly to predators fed on a diet of conspecifics, showed a weak response to predators fed on green sea urchins and did not respond to a starved predator. The failure of black sea urchins to respond to hungry cushion sea stars probably increases their risk of being consumed. Black sea urchins, however, responded strongly to injured conspecific and, to a lesser degree, to heterospecific prey. In addition to the dilution effect imposed by the habit of living in dense assemblages, black sea urchins use the defence strategy of detecting an upcoming threat via chemical cue from injured prey when cues emanating from the echinivorous predator itself are not detectable.
\end{abstract}

KEY WORDS: Chemical communication - Defensive behaviour - Echinoderms · Predation risk • Predator-prey system · Sympatric prey

Resale or republication not permitted without written consent of the publisher

\section{INTRODUCTION}

Aquatic animals use chemical cues to relate to their environment in a number of ways, including predator recognition and antipredator behaviour (Chivers \& Smith 1998, Jacobsen \& Stabell 2004, Hay 2009). These cues are easily used because they quickly dissolve and spread in the water, becoming extremely relevant when visibility is low (Wisenden 2000, Zimmer \& Butman 2000, Weissburg et al. 2002). Chemical cues are especially important to animals with rudimentary photoreception, such as sea urchins (Mann et al. 1984, Campbell et al. 2001, Hagen et al. 2002).

In the context of predator-prey dynamics, chemical cues directly or indirectly indicate the presence of a predator, either by the physical presence of a predator odour (Wisenden 2000) or by chemical cues from threatened (Jordão \& Volpato 2000, Barcellos et al. 2011) or injured (Chivers \& Smith 1998) prey. Perception of chemical cues has important implications for prey survival because it allows prey animals to anticipate a potential predator attack and to employ antipredator responses accordingly (Chivers \& Smith 1998, Kats \& Dill 1998).

The direct detection of a predator depends upon recognition of predator odours (Magurran 1989, Lima \& Dill 1990, Kiesecker et al. 1996). In both vertebrates and invertebrates, chemical cue dilution and predator diet influence detection of predator odours which elicit antipredator reponses by potential prey (Chivers et al. 1996, Hagen et al. 2002, Jacobsen \& Stabell 2004, Fraker 2008). However, some animals display antipredator response in an 'all-or-nothing' manner if the predator odour is above a threshold level (Brown et al. 2001, Mirza \& Chivers 2003). 
Indirect detection occurs in response to chemical cues released from prey. The most common chemical cues come from injury of a prey animal as a result of predator attack. For instance, putative chemical alarm cues are thought to be produced and stored in the epidermal 'club' cells of some fish and are released when the epidermis is damaged (Chivers \& Smith 1998, Barreto et al. 2010, Barbosa Júnior et al. 2010). Although this kind of chemical communication occurs in invertebrates, there is no clear evidence regarding any type of alarm substance-producing cells in these animals (Hagen et al. 2002, Kicklighter et al. 2005, Griffiths \& Richardson 2006, Smee \& Weissburg 2006a, Moir \& Weissburg 2009). In invertebrates, the chemicals released by injured prey appear more likely to be prey metabolites (e.g. Howe \& Sheikh 1975, Pelletier 2004, Kicklighter et al. 2007; reviewed by Zimmer \& Zimmer 2008). Moreover, some animals respond dramatically to injured prey metabolites, while responding with less intensity to predator metabolites, indicating hierarchical responses of risk perception (Keppel \& Scrosati 2004, Smee \& Weissburg 2006a, Large \& Smee 2010).

The idea of chemical alarm perception and recognition as the initial step of defensive behaviour has been studied in vertebrates and invertebrates. Amongst the invertebrates, however, little research has been done on this topic in echinoids (Mann et al. 1984, Campbell et al. 2001, Hagen et al. 2002), despite the obvious relevance of chemoreception in these animals.

The scarce data on echinoids indicates that they are able to chemically recognise predators (direct detection), especially when the predator has eaten conspecific prey (predator labelling), as shown for the green sea urchin Strongylocentrotus droebachiensis (Mann et al. 1984, Hagen et al. 2002), and that they respond to alarm cues from conspecifics (indirect detection), as reported for the sea urchins Echinus esculentus and Psammechinus miliaris (Campbell et al. 2001) and, analysing locomotion only, for Echinometra viridis, Echinometra lucunter, Lytechinus variegatus, L. williamsi, Tripneustes ventricosus, Diadema antillarum, but not Eucidaris tribuloides (Parker \& Shulman 1986).

In aquatic ecosystems, chemical cues indicating risk of predation may come from predators labelled by consuming either conspecific or heterospecific prey, or from injured conspecific or heterospecific prey (Chivers \& Smith 1998, Kats \& Dill 1998, Weissburg et al. 2002, Smee \& Weissburg 2006a, Zimmer \& Zimmer 2008, Hay 2009, Selden et al. 2009, Large \& Smee 2010). Sea urchin predators are usually generalists, eating several prey species. Some sea urchins have evolved to cohabit with other potential prey that were under predation pressure from the same predators. Hence, it is plausible to hypothesise that heterospecific cues from sympatric prey of a sea urchin species might also be relevant for sea urchin antipredator responses. The cushion sea star Oreaster reticulatus is a generalist predator that preys upon sea urchins, including Echinometra spp. (Scheibling 1982, Gandolfi 2003) and Lytechinus variegatus (Martín et al. 2001), among others, which cohabit in the same rocky coast environments (Jerez et al. 2001). In the present study, we evaluated in 2 separate experiments the direct and the indirect detection of predators by black sea urchin. We measured the behavioural reaction (1) to odour of the echinivorous predator $O$. reticulatus and, as a control, to the non-echinivorous starfish Echinaster brasiliensis fed a diet of different sympatric prey species (the urchins Echinometra lucunter and L. variegatus, and the mussel Perna perna as control stimulus) and (2) to alarm cues from these injured prey.

\section{MATERIALS AND METHODS}

Animals and holding conditions. Specimens of black sea urchins Echinometra lucunter (Linnaeus, 1758), green sea urchins Lytechinus variegatus (Lamarck, 1816), brown mussel Perna perna (Linnaeus, 1758), cushion sea star Oreaster reticulatus (Linnaeus, 1758), and red starfish Echinaster brasiliensis Müller and Troschel, 1842, were collected by SCUBA diving in São Sebastião city, São Paulo state, Brazil. The animals were brought to the animal stock facility at the Center of Marine Biology of São Paulo University (CEBIMar/ USP). They were cleaned for $1 \mathrm{~h}$ in a constant flow of filtered seawater. Starfish, green sea urchins and mussels were then placed into separated stock tanks with a constant flow of seawater until required for experimentation. The animals were kept under $12 \mathrm{~h}$ of light and $12 \mathrm{~h}$ of dark with artificial illumination.

Experiment 1: effects of predator odour on black sea urchin behaviour. This experiment evaluated sea urchin behaviour when exposed to odours of echinivorous and non-echinivorous starfish fed on different prey species. We used 10 experimental glass tanks $(50 \times 20 \times$ $50 \mathrm{~cm}$; water volume $=25 \mathrm{l}$; water column $=10 \mathrm{~cm}$, the approximate height of the sea urchins) that were always washed with glass detergent and rinsed with abundant fresh water before reuse. Black sea urchins were placed into experimental tanks in batches of 5 animals per tank for an acclimation period of $24 \mathrm{~h}$ with a constant flow of seawater. The inflow of seawater was then interrupted, and the tanks were maintained with continuous aeration for $1 \mathrm{~h}$, after which the behaviour of the black sea urchins was quantified for 5 min (baseline measurement). They were then exposed to a chemical stimulus in the form of $500 \mathrm{ml}$ odour that was carefully poured onto the water surface and their behaviour was recorded for $15 \mathrm{~min}$. The odours were prepared as de- 
scribed below from echinivorous starfish that were either unfed (hungry) or fed on black or green sea urchins (the sympatric prey species). To control for the possible effect of any unspecific odour, 2 control groups of black sea urchins were exposed to the odour of either an echinivorous or non-echinivorous starfish fed on brown mussels Perna perna; this is an exotic species that has been present in Brazil for centuries and is a food item for several predators (López et al. 2010). A further group was placed in the odour diluent, artificial seawater, to control experimental procedures. Thus, 6 independent experimental treatments were conducted $(\mathrm{n}=$ 10 batches of 5 urchins each; no sea urchin was reused in any treatment). The temporal sequence of the different treatments was randomly determined by drawing lots and the treatments were also randomly allocated to each experimental tank. The mean $( \pm \mathrm{SD})$ diameter of black sea urchin tests was $5.28 \pm 0.28 \mathrm{~cm}$, a small range in variation to avoid size-specific effects (Selden et al. 2009).

For odour preparation, each individual starfish was reared in isolation in a tank $(41.0 \times 56.0 \times 78.0 \mathrm{~cm}$ or $17.5 \times 44.5 \times 68.5 \mathrm{~cm}$ for Oreaster reticulatus or Echinaster brasiliensis, respectively) with constant flow of seawater for $7 \mathrm{~d}$. Each starfish was fed an amount of food equivalent to $5 \%$ of the animal's body weight. The food was consumed in a period of $24 \mathrm{~h}$. As pilot observations showed that starfish ate only the gonads of sea urchins and left the gut contents intact, the diet consisted of black or green sea urchin gonads (echinivorous starfish), mussels removed from their shells (echinivorous and non-echinivorous starfish), or no food (echinivorous starfish). Next, each starfish was removed from its tank, rinsed in abundant running seawater and placed into a new tank (still in isolation) containing artificial seawater for $24 \mathrm{~h}$. Artificial seawater was used to avoid any environmental scent that might be present in natural seawater. During this time, tanks were provided with constant aeration, without any filtration procedure. The conditioned water was then filtered through glass wool to remove any remaining particles (Chivers \& Smith 1994). Because starfish vary in weight, we adjusted the odour volume by adding artificial seawater to reach a standardised body mass:volume ratio of $300 \mathrm{~g}$ of predator body mass per 21 of odour (see Table 1 for details). The odours were divided into aliquots of $500 \mathrm{ml}$, bottled in plastic containers, and frozen at $-20^{\circ} \mathrm{C}$ ) until required for experimentation (Hagen et al. 2002).

Experiment 2: effects of conspecific and heterospecific extracts (alarm cues) on black sea urchin behaviour. To assess whether black sea urchins respond to chemical cues from conspecific and heterospecific sympatric prey physically injured by a predator, a similar experiment schedule to that described above was conducted, using different chemical stimuli. In this case, the chemical stimuli were extracts of black or green sea urchins, mussels and, as a control, unconditioned artificial seawater. Thus, 4 independent experimental treatments were conducted ( $\mathrm{n}=10$ batches of 5 urchins each; no sea urchin was reused in any treatment). The mean diameter of black sea urchin tests was $5.39 \pm 0.41 \mathrm{~cm}$.

Each extract was prepared using crushed sea urchins extracted in seawater (100 g of each prey animal in $500 \mathrm{ml}$ of artificial seawater). Each solution was filtered through glass wool to remove any remaining particles (Chivers \& Smith 1994), and $80 \mathrm{ml}$ were diluted in $5 \mathrm{l}$ of artificial seawater, then separated in aliquots of $500 \mathrm{ml}$ and frozen for later use (Hagen et al. 2002).

Behavioural quantification. We used a binary classification to quantify the extension of the tube feet and movement of spines. We assigned the value 1 when the behaviour occurred and 0 in its absence. The behaviours recorded were (i) extension of tube feet, where the tube feet could be retracted (0) or extended (1), and (ii) spine movement, where the animal frantically moved the spines (1) or no clear movement was detected (0). These procedures were based on Morishita et al. (2009).

To measure the aggregation of sea urchins, we counted the number of animals that were connected by

Table 1. Odour preparation for testing the effects of predator odour on black sea urchin behaviour. Echinivorous predator: cushion sea star Oreaster reticulates; non-echinivorous predator: red starfish Echinaster brasiliensis; prey species: black sea urchin Echinometra lucunter, green sea urchin Lytechinus variegatus, mussel Perna perna. Diluent: artificial seawater. Odour concentration was standardised by adding artificial seawater to reach a body mass:volume ratio of $300 \mathrm{~g}$ of predator body mass per 21 of odour

\begin{tabular}{|llccc|}
\hline Stimulus & Diet type & Predator body mass (g) & Food quantity (g) & Total odour volume (l) \\
\hline Echinivorous predator & Black sea urchin & 1245 & 62.25 & 8.30 \\
& Green sea urchin & 1285 & 64.25 & 8.57 \\
& Brown mussel & 1750 & 87.5 & 11.67 \\
Non-echinivorous predator & No food & 2150 & 0.0 & 14.33 \\
Control diluent & - & 755 & 37.75 & 5.03 \\
& - & - & 5.00 \\
\hline
\end{tabular}


Table 2. Echinometra lucunter. Aggregation behaviour measurement criteria for black sea urchin

\begin{tabular}{|cc|}
\hline Examples of aggregations & Values scored \\
\hline 0 & 0 \\
0 & 1 \\
0 & 2 \\
& 2 \\
\hline
\end{tabular}

interlaced spines. We did not consider how many spines were in contact, but aggregation always involved $\geq 10$ spines of each sea urchin. Scores were calculated as shown in Table 2 . In addition, the bottom of the aquarium was divided into quadrants of $10 \mathrm{~cm}$, and the position of each animal in space was estimated at 1 min intervals by identifying the quadrant occupied by the largest portion of the sea urchin. These data were arranged in $x-y$ axes. The average positions of each urchin in the $x$-axis and $y$-axis were the barycentre coordinates (the point at the centre of a system), and were calculated during the $5 \mathrm{~min}$ baseline measurements and in 3 blocks of 5 min during the $15 \mathrm{~min}$ period of observation after stimuli presentation. The aquaria had no structure that limited urchins' movement. The water depth was slightly greater than the height of the urchins, allowing us to consider their displacement through the aquaria in a 2-dimensional way, because if an urchin was stuck on the tank wall it was occupying practically the same place as it was on the adjacent bottom quadrant. In this way, we were able to measure the dispersion, which represents the mean distance between each position of a sea urchin on the grid and its respective barycentre. As dispersion values increased, the displacement of an animal throughout the aquarium became broader. This procedure was adapted from earlier work of Thines \& Vandenbussche (1966) and Jordão \& Volpato (2000) for fish which has been successfully applied and validated for sea urchins (Morishita et al. 2009).

Statistical analyses. The statistical unit of analyses was the batch of 5 sea urchins. We first obtained the average values of each batch at each sampling time interval (Baseline: $-05: 00$ to 00:00 $\mathrm{min}$; post-stimuli: 00:00 to $05: 00,05: 01$ to $10: 00$, and 10:01 to $15: 00 \mathrm{~min}$ ). Second, the difference between the means of these post-stimuli values and the mean baseline values was determined for each batch, allowing each batch to act as its own control. Finally, these 3 obtained differences were then averaged for statistical analyses. The normality and homoscedasticity of the data were evaluated by the Kolmogorov-Smirnov (KS) test and Bartlett's test, respectively. In cases where the KS test showed that the data were sampled from populations that did not follow normal distributions and Bartlett's test indicated that the differences among the SDs were statistically significant, we used a Kruskal-Wallis ANOVA test complemented by a Dunn test when necessary. In cases where the data met the assumptions of normality and homoscedasticity, we applied 1-way ANOVA complemented by a Student-NewmanKeuls test. Statistical differences were considered significant at $\alpha=0.05$.

\section{RESULTS}

\section{Experiment 1: effects of predator odour on black sea urchin behaviour}

The 1-way ANOVA revealed significant differences for tube feet extension response $\left(F_{(5,54)}=5.358 ; \mathrm{p}<\right.$ 0.001; Fig. 1A). The black sea urchins showed a significant increase in tube feet extension in response to an odour of echinivorous starfish fed on conspecific or heterospecific echinoid prey in comparison to odours from starved echinivorous starfish, non-echinivorous starfish fed on mussels and pure artificial seawater (control diluent). Moreover, the response of black sea urchins to odours from echinivorous starfish fed on mussels was higher than to the control diluent but similar to the remaining odours.

The spine movement responses of black sea urchins were significantly higher (1-way ANOVA, $F_{(5,54)}=$ 4.727; $p=0.0012$; Fig. 1B) when exposed to odours of echinivorous starfish fed on conspecific prey than for any other odour, and the responses to other odours were statistically similar to each other.

There were no differences between the aggregation (Kruskal-Wallis ANOVA test, $H=3.589 ; \mathrm{p}=0.61$; Fig. 1C) or dispersion (Kruskal-Wallis ANOVA test, $H=1.556$; $\mathrm{p}=0.91$; Fig. 1D) of black sea urchin among all odour treatments.

\section{Experiment 2: effects of conspecific and} heterospecific extracts on black sea urchin behaviour

The 1-way ANOVA showed statistical differences in tube feet responses $\left(F_{(3,36)}=4.737, \mathrm{p}=0.0069\right.$; Fig. 2A). We found that black sea urchins extended their tube feet in response to conspecific extract at a similar level to heterospecific sea urchin extract but at a higher level than to mussel extract and pure artificial seawater. The responses of sea urchins to these last 3 extracts were similar.

Any extract containing an animal chemical cue induced a significant increase in movements of spine in comparison to control diluent (1-way ANOVA, $F_{(3,36)}=$ 

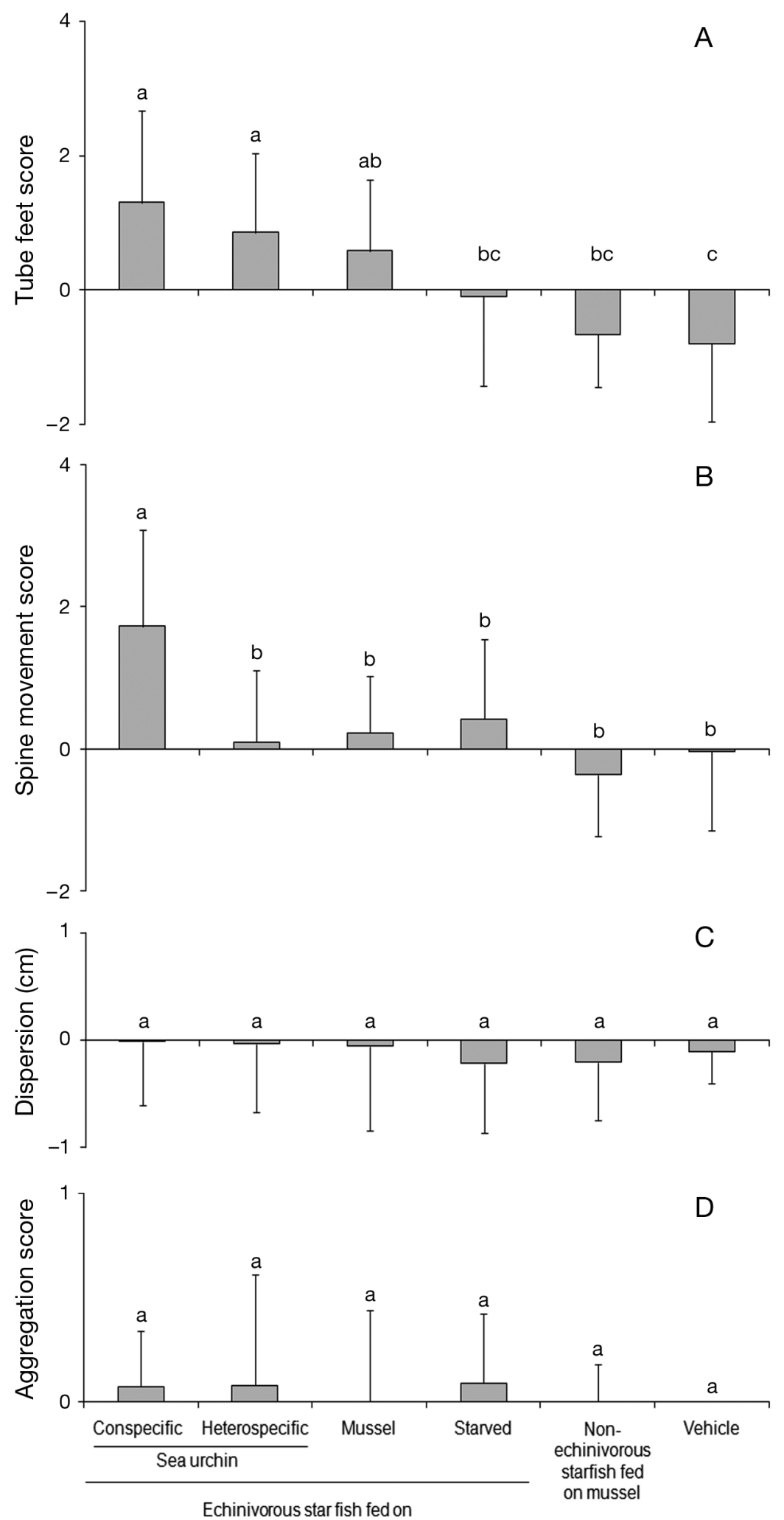

Fig. 1. Echinometra lucunter. Effect of predator diet on behavioural responses to predator odour in black sea urchins: (A) tube feet extension; (B) spine movement; (C) dispersion; and (D) aggregation. Means that do not share the same letter are significantly different $(\mathrm{p}<0.05)$ using 1-way ANOVA $(\mathrm{A}, \mathrm{B})$ or Kruskal-Wallis ANOVA $(\mathrm{C}, \mathrm{D})$
10.44, p < 0.0001; Fig. 2B), but the magnitude of the responses was statistically similar.

We found no statistical difference in locomotion response (dispersion) of black sea urchins to any chemical cues from prey extracts (Kruskal-Wallis ANOVA test, $H=1.071, \mathrm{p}=0.78$; Fig. 2C). However, black sea urchins showed higher rates of interlaced spines (aggregation) in response to the extract of conspecific prey compared to the mussel extract and control diluent (Kruskal-Wallis ANOVA test, $H=10.34$; $\mathrm{p}=0.0016 ;$ Fig. 2D). The aggregation in response to extract of heterospecific sea urchins was similar to responses obtained for the remaining treatments.

\section{DISCUSSION}

\section{Defensive behaviour induced by odours from predators fed on different diets}

In this study, black sea urchin tube feet were extended in response to odour of the echinivorous starfish predator Oreaster reticulatus; this behaviour was, however, dependent upon predator diet. The most evident tube feet response of black sea urchin was to the predator fed on conspecific prey. The consumption of any prey induces tube feet response, but echinoid prey seems to induce a stronger response in black sea urchins than mussels. The tube feet response became gradually less prominent as the phylogenetic distance among the prey species used for labelling the predator odour increased. Unfed echinivorous predator, and non-echinivorous predator (Echinaster brasiliensis) odours elicited no response. The response of extended tube feet in black sea urchins to different odours of echinivorous starfish predators depends on the prey consumed. The black sea urchins in our study were able to distinguish echinivorous from non-echinivorous starfish; similarly, Scheibling Hamm (1991) found that sea urchins Strongylocentrotus droebachiensis responded to the odour of the echinivorous crab Cancer irroratus but not to the odour of the non- 

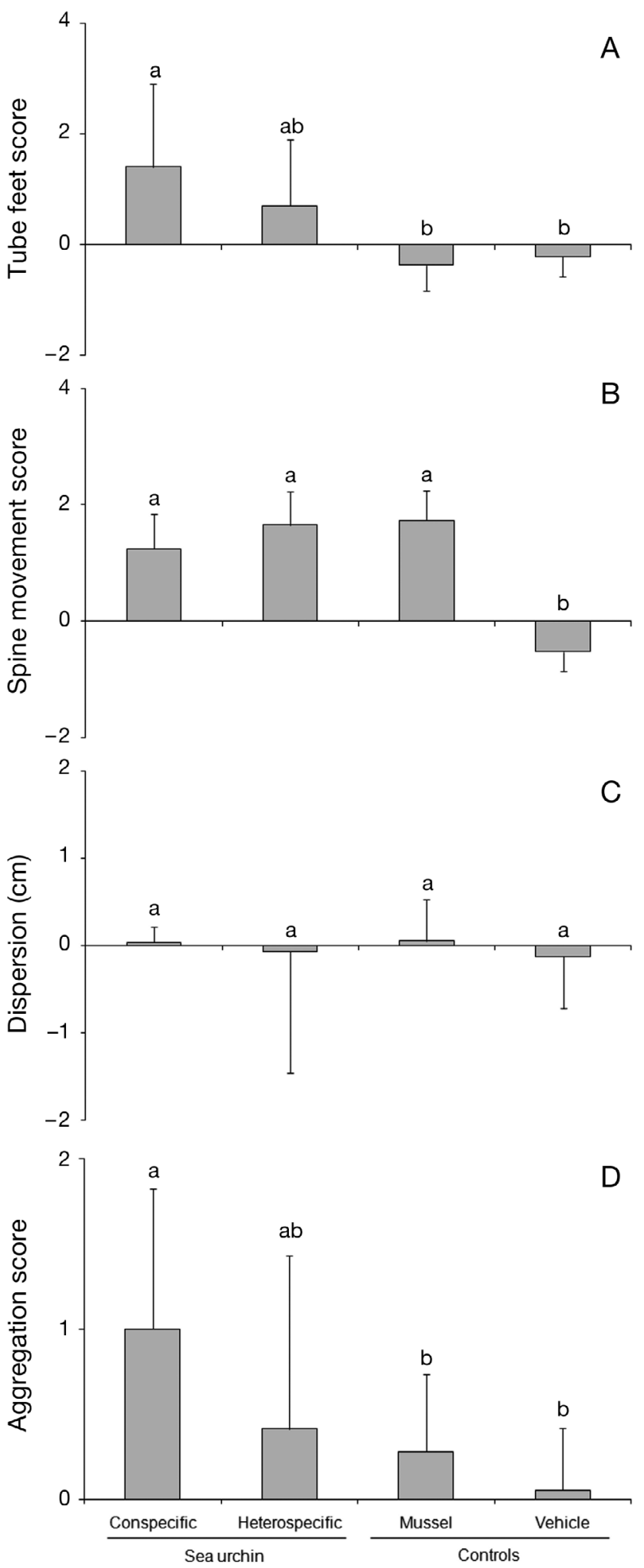

Fig. 2. Echinometra lucunter. Effect of chemical cues from injured conspecific and heterospecific prey on behavioural responses of black sea urchins: (A) tube feet extension; (B) spine movement; (C) dispersion; and (D) aggregation. Means that do not share the same letter are significantly different $(p<0.05)$ using 1-way ANOVA (A,B) or Kruskal-Wallis ANOVA $(\mathrm{C}, \mathrm{D})$ echinivorous crab, Carcinus maenas. Finally, the sea urchins that received unconditioned odour diluent seemed to reduce tube feet activity. Sea urchin activity decreases abruptly in still water, as reported for Strongylocentrotus nudus (Kawamata 1998). In the present study, the seawater inflow was interrupted during behavioural quantification, which is a potential explanation for the reduction in the tube feet responses.

In contrast to the findings of Hagen et al. (2002) that ca. $50 \%$ of sea urchins Strongylocentrotus droebachiensis exposed to the odour of Atlantic wolffish Anarhichas lupus which had been fed on conspecific sea urchin ceased movement, black sea urchins in our study did not respond by altering their locomotor activity or aggregation. Instead, they increased spine movement when exposed to the odour of echinivorous starfish fed on conspecific prey, the only odour in the predator diet experiments to elicit such a response. During acts of predation, fish and crabs remove sea urchins from the substrate and consume them through the oral region, whereas starfish evert their stomachs into the interior of the urchins, usually through the anal orifice and, therefore, do not have to remove them from the substrate (Brusca \& Brusca, 2003). Different patterns of response are necessary to account for the predators foraging at a given location. Black sea urchin spine movement is assumed to be an efficient method of decreasing starfish predation but not predation from other potential predators with different predation strategies, such as fish and crabs. This might explain the difference in results between this experiment and those reported by Hagen et al. (2002).

Sea urchins' tube feet and spines both have chemical and mechanical receptors (Sloan \& Campbell, 1982). The tube feet are structures used frequently for chemoreception (Raible et al. 2006), whereas the spines offer greater protection. Combining the black sea urchin tube feet and spine responses, we conclude that black sea urchin showed more pronounced responses to the odour of echinivorous starfish fed on black sea urchin conspecifics compared to the other odours. Although they evaluated the surrounding chemical cues displaying a variety of tube feet responses when experiencing different odours, a defensive response (spine movement) was induced only by the odour of echinivorous starfish labelled by a conspecific diet. Black sea urchins chemically recognise Oreaster reticulatus as a predator and display antipredator behaviour when this predator consumes a conspecific prey. Other chemical labels, although they elicited sensory response (tube feet extension), were not able to induce a defensive behaviour (spine response), which indicates no clear predator recognition without the conspecific label. Hagen et al. (2002) also report that, when the predator feeds on conspecific prey, the response is more intense than is 
displayed for the stimulus of a predator fed on heterospecific animals.

The black sea urchin was clearly able to detect and react to an odour of the starfish predator fed a conspecific diet. However, the ability to recognise starved predators may be even more important for survival, given the obvious increased motivation of the predator to eat. The failure of black sea urchins to react to starved cushion sea stars likely increases their vulnerability to these consumers.

\section{Defensive behaviour elicited by chemical alarm cues}

Urchins' responses to injured prey may constitute a strategy that allows animals to detect an imminent threat when signals emanating from the predator are not clearly detectable, such as in the case of a starved predator. This might well be a widespread strategy of animals to deal with predators, as similar responses have been reported for the molluscs, hard clam Mercenaria mercenaria (Smee \& Weissburg 2006a) and dog whelk Nucella lapillus (Large \& Smee, 2010), and for the frog Rana temporaria (Capellán \& Nicieza 2010).

As previously reported, black sea urchins react by moving away from the source of chemical alarm cues from conspecifics and a congener (Echinometra viridis) (Parker \& Shulman 1986). In the present study, black sea urchins had a clear tube feet response to an injured conspecific. They also had a weak tube feet response to injured heterospecific green sea urchins Lytechinus variegatus, but not to injured mussels. The aggregation behaviour followed the same response pattern. The tube feet and aggregation reactions suggest at least 2 possible explanations. First, the cue might be species-specific but might have some chemical similarities in the echinoid group. Second, the same chemical(s) may also occur in different concentrations in each species, modulating the magnitude of the response. Moreover, the absence of tube feet extension or aggregation when exposed to injured mussel cue would also suggest that the mussels do not produce a cue which black sea urchins recognise and respond to. This may be due to the fact that the mussel Perna perna is an exotic species, although it has been found in the Brazilian environment for centuries. However, the response of the spines indicates that black sea urchins recognise chemical cues from the mussel to some extent. The chemical cues from all injured prey animals, including mussels, elicited increased spine movement of a similar magnitude. However, the global response strength decreased as the phylogenetic distance among the injured prey increased. The ability of black sea urchins to detect cues from injured conspecifics and, to a lesser extent, from other heterospe- cific prey species might be a strategy to respond to a foraging predator when it is starved and, therefore, not easily recognisable because of the absence of a specific odour. In other words, the presence of injured prey species indicates the nearby presence of a predator that is highly motivated to eat.

\section{Potential ecological significance}

Black and green sea urchins are abundant species which co-exist in some patches in their environment (Jérez et al. 2001). Both are preyed on by cushion sea stars (Martín et al. 2001, Guzmán \& Guevara 2002). This scenario suggests that they evolved under the same predation pressure and were exposed to the same sensory cues during the course of their evolution. In this study, we found that defensive responses in black sea urchins were triggered by cues from conspecific and, to some extent, from heterospecific green sea urchins, both in the form of labelled predator odour and as diluted extracts of injured prey. However, the odour of a starved predator was not clearly recognised, and no response was observed. The defensive strategy of black sea urchins consists of evaluating the predator odour and, when they cannot detect an imminent threat or when the signal emanating from the predator is not detectable, the cue from an injured conspecific or even heterospecific animal is used for defence. The ability of black sea urchins to react to injured conspecifics may compensate for their inability to detect starved cushion sea stars. They may benefit from living in close proximity to conspecific and heterospecific related echinoids, as neighbours can provide shared vigilance against predators or early warnings of potential threat (Hamilton 1971, Fitzgibbon 1990, Smee \& Weissburg 2006a, Large \& Smee 2010, Capellán \& Nicieza 2010, Hughes \& Banks 2010). This benefit provided by neighbours is particularly relevant in species that recognise chemical cues from injured conspecific and/or heterospecific animals, as consumption of a neighbour indicates a predation risk.

In addition to the ability to recognise and respond to chemical cues of injured conspecific and heterospecific prey animals, the dilution effect of living in dense assemblages becomes extremely relevant for reducing the possibility of predation by cushion sea stars. Black sea urchins live in dense groups and show pronounced aggregation near food patches (Metaxas \& Young 1998a, 1998b). This has a potential dilution effect when prey are exposed to a foraging predator because for any one predator attack, the larger the group of prey animals, the smaller the chance that any particular individual will be the victim (Foster \& Treherne 1981). 


\section{Final considerations}

Although we were able to determine certain behavioural responses to heterospecific cues, the results are currently ambiguous with respect to the importance of cues from heterospecific prey animals because the findings are that prey react weakly (sensory response only) to the odour of predator-fed heterospecific prey, whereas they respond more strongly (sensory and defensive reactions) to heterospecific prey metabolites. This may indicate some hierarchy of salience, as metabolites from injured animals may indicate a more immediate threat; so it makes sense to pay attention to heterospecific cues. The variation regarding the importance of heterospecific chemical cues may also stem from limitations of the experimental study in that the collection of these odour sources occurred over arbitrary time periods, and the amount introduced was also arbitrary, as neither the chemical nature nor the temporal dynamic of production of the cues in sea urchins is known. Thus, there is no way to ensure that the concentrations of injured prey metabolites or the dietconditioned predator metabolites experienced by prey in the experiments match those present in their natural environment. This might account for the ambiguous results, and future studies must clarify this issue in sea urchins, assuring appropriate scaling, where cues from predators fed prey, or injured conspecifics, are delivered by a flow comparable to those which would occur in the field. Furthermore, many animals use flow as an accessory stimulus, as the water flow can enhance or impair the chemoreception ability of risk detection by prey animals (Smee \& Weissburg 2006b, Zimmer \& Zimmer 2008, Large et al. 2011). In the present study, flow was not considered as an independent variable. Flow would modulate the dispersion of the cue, even if it dispersed quickly throughout the test tank. Thus, this aspect also should be tested in future studies in sea urchins.

The aggregating behaviour of black sea urchins to injured prey cues was clear and matched the response of tube feet. This behaviour, however, was not evident in black sea urchins exposed to predator odours. Further studies using alternative methods of measuring aggregation, such as those previously applied to Strongylocentrotus droebachiensis (Hagen \& Mann 1994), must be tested in this sea urchin species.

Acknowledgements. The authors thank A. E. Migotto for allowing this study to be carried out in the facilities of the CEBIMar - USP (Center of Marine Biology of São Paulo University) and also for providing all background support. We also thank G. L. Volpato and R. A. Christofoletti for valuable suggestions on the first draft of this manuscript. V.R.M. received financial support from a scholarship awarded by CAPES (Coordenação de Aperfeiçoamento de Pessoal de Nível Superior), Brazil.

\section{LITERATURE CITED}

Barbosa Júnior A, Magalhães EJ, Hoffmann A, Ide LM (2010) Conspecific and heterospecific alarm substance induces behavioural responses in piau fish Leporinus piau. Acta Ethol 13:119-126

> Barcellos LJG, Volpato GL, Barreto RE, Coldebella I, Ferreira D (2011) Chemical communication of handling stress in fish. Physiol Behav 103:372-375

Barreto RE, Barbosa A, Giassi ACC, Hoffmann A (2010) The club cell and behavioural and physiological responses to chemical alarm cues in the Nile tilapia. Mar Freshw Behav Physiol 43:75-81

Brown GE, Adrian JC, Patton T, Chivers DP (2001) Fathead minnows learn to recognize predator odour when exposed to concentrations of artificial alarm pheromone below their behavioural-response threshold. Can J Zool 79:2239-2245

Brusca RC, Brusca GJ (2003) Invertebrates, 2nd edn. Sinauer Associates, Sunderland, MA

> Campbell AC, Coppard S, D'Abreo C, Tudor-Thomas R (2001) Escape and aggregation responses of three echinoderms to conspecific stimuli. Biol Bull 201:175-185

> Capellán E, Nicieza AG (2010) Constrained plasticity in switching across life stages: pre- and post-switch predators elicit early hatching. Evol Ecol 24:49-57

Chivers DP, Smith JF (1994) Fathead minnows, Pimephales promelas, acquire predator recognition when alarm substance is associated with the sight of unfamiliar fish. Anim Behav 48:597-605

Chivers DP, Smith JF (1998) Chemical alarm signalling in aquatic predator-prey systems: a review and prospectus. Ecoscience 5:338-352

Chivers DP, Wisenden BD, Smith JF (1996) Damselfly larvae learn to recognize predators from chemical cues in the predator's diet. Anim Behav 52:315-320

> Fitzgibbon CD (1990) Mixed-species grouping in Thomson's and Grant's gazelles: the antipredator benefits. Anim Behav 39:1116-1126

> Foster WA, Treherne JE (1981) Evidence of the dilution effect in the selfish herd from fish predation on a marine insect. Nature 293:466-467

Fraker ME (2008) The dynamics of predation risk assessment: responses of anuran larvae to chemical cues of predators. J Anim Ecol 77:638-645

Gandolfi SM (2003) Feeding behaviour and motivation of the starfish Oreaster reticulatus in a benthic community of infralittoral of Arquipélago das Três Ilhas, Guarapari (in Portuguese with English abstract). PhD thesis, Institute of Biosciences, University of São Paulo

Griffiths CL, Richardson CA (2006) Chemically induced predator avoidance behaviour in the burrowing bivalve Macoma balthica. J Exp Mar Biol Ecol 331:91-98

- Guzmán HM, Guevara CA (2002) Annual reproductive cycle, spatial distribution, abundance and size structure of Oreaster reticulatus (Echinodermata: Asteroidea) in Bocas del Toro, Panama. Mar Biol 141:1077-1084

> Hagen NT, Mann KH (1994) Experimental analysis of factors influencing the aggregating behavior of the green seaurchin Strongylocentrotus droebachiensis (Muller). J Exp Mar Biol Ecol 176:107-126

> Hagen NT, Andersen A, Stabell OB (2002) Alarm responses of the green sea urchin, Strongylocentrotus droebachiensis, induced by chemically labeled durophagous predators and simulated acts of predation. Mar Biol 140: 365-374

> Hamilton WD (1971) Geometry for the selfish herd. J Theor Biol 31:295-311 
Hay ME (2009) Marine chemical ecology: chemical signals and cues structure marine populations, communities, and ecosystems. Ann Rev Mar Sci 1:193-212

Howe NR, Sheikh YM (1975) Anthopleurine-sea anemone alarm pheromone. Science 189:386-388

Hughes NK, Banks PB (2010) Interacting effects of predation risk and signal patchiness on activity and communication in house mice. J Anim Ecol 79:88-97

$>$ Jacobsen HP, Stabell OB (2004) Antipredator behaviour mediated by chemical cues: the role of conspecific alarm signalling and predator labelling in the avoidance response of a marine gastropod. Oikos 104:43-50

Jérez PS, Cesar A, Cortez FS, Pereira CDS, Silva SLR (2001) Spatial distribution of the most abundant sea urchin populations on the southeast coast of São Paulo (Brazil). Cienc Mar 27:139-153

Jordão LC, Volpato GL (2000) Chemical transfer of warning information in non-injurid fish. Behaviour 137:681-690

Kats LB, Dill LM (1998) The scent of death: chemosensory assessment of predation risk by prey animals. Ecoscience 5:361-394

Kawamata S (1998) Effect of wave-induced oscillatory flow on grazing by a subtidal sea urchin Strongylocentrotus nudus (A. Agassiz). J Exp Mar Biol Ecol 224:31-48

Keppel E, Scrosati R (2004) Chemically mediated avoidance of Hemigrapsus nudus (Crustacea) by Littorina scutulata (Gastropoda): effects of species coexistence and variable cues. Anim Behav 68:915-920

Kicklighter CE, Shabani S, Johnson PM, Derby CD (2005) Sea hares use novel antipredatory chemical defenses. Curr Biol 15:549-554

Kicklighter CE, Germann M, Kamio M, Derby CD (2007) Molecular identification of alarm cues in the defensive secretions of the sea hare Aplysia californica. Anim Behav 74: 1481-1492

Kiesecker JM, Chivers DP, Blaustein AR (1996) The use of chemical cues in predator recognition by western toad tadpoles. Anim Behav 52:1237-1245

Large SI, Smee DL (2010) Type and nature of cues used by Nucella lapillus to evaluate predation risk. J Exp Mar Biol Ecol 396:10-17

Large SI, Smee DL, Trussell GC (2011) Environmental conditions influence the frequency of prey responses to predation risk. Mar Ecol Prog Ser 422:41-49

Lima SL, Dill LM (1990) Behavioural decisions made under the risk of predation: a review and prospectus. Can J Zool 68:619-640

López MS, Coutinho R, Ferreira CEL, Rilov G (2010) Predatorprey interactions in a bioinvasion scenario: differential predation by native predators on two exotic rocky intertidal bivalves. Mar Ecol Prog Ser 403:101-112

Magurran AE (1989) Acquired recognition of predator odour in the European minnow (Phoxinus phoxinus). Ethology 82:216-223

Mann KH, Wright JLC, Welsford BE, Hatfield E (1984) Response of the sea urchin Strongylocentrotus droebachiensis (O. F. Müller) to water-borne stimuli from potential predators and potential food algae. J Exp Mar Biol Ecol 79:233-244

Martín A, Penchaszadeh P, Atienza D (2001) Densidad y hábitos alimentarios de Oreaster reticulatus (Linnaeus, 1758) (Echinodermata, Asteroidea) en praderas de fan-

Editorial responsibility: Peter Steinberg,

Sydney, New South Wales, Australia erógamas marinas de Venezuela. Bol Inst Esp Oceanogr 17:203-208

Metaxas A, Young CM (1998a) Responses of echinoid larvae to food patches of different algal densities. Mar Biol 130: 433-445

Metaxas A, Young CM (1998b) Behaviour of echinoid larvae around sharp haloclines: effects of the salinity gradient and dietary conditioning. Mar Biol 131:443-459

Mirza RS, Chivers DP (2003) Influence of body size on the responses of fathead minnows, Pimephales promelas, to damselfly alarm cues. Ethology 109:691-699

- Moir F, Weissburg MJ (2009) Cautious cannibals: behavioral responses of juvenile and adult blue crabs to the odor of injured conspecifics. J Exp Mar Biol Ecol 369:87-92

Morishita VR, Buchmann FSC, Christofoletti RA, Volpato GL, Barreto RE (2009) Prior residence and body size influence interactions between black sea urchins. Behav Processes 80:191-195

Parker DA, Shulman MJ (1986) Avoiding predation: alarm responses of Caribbean sea urchins to simulated predation on conspecific and heterospecific sea urchins. Mar Biol 93: 201-208

> Pelletier N (2004) Conspecific injury fluids induce an electrophysiological response in the clonal tunicate Clavelina huntsmani. Mar Biol 145:1159-1165

Raible F, Tessmar-Raible K, Arboleda E, Kaller T, Bork P, Arendt D, Arnone MI (2006) Opsins and clusters of sensory G-protein-coupled receptors in the sea urchin genome. Dev Biol 300:461-475

Scheibling RE, Hamm J (1991) Interactions between sea urchins (Strongylocentrotus droebachiensis) and their predators in field and laboratory experiments. Mar Biol 110:105-116

Scheibling RE (1982) Feeding habits of Oreaster reticulatus (Echinodermata: Asteroidea). Bull Mar Sci 32:504-510

Selden R, Johnson AS, Ellers O (2009) Waterborne cues from crabs induce thicker skeletons, smaller gonads and sizespecific changes in growth rate in sea urchins. Mar Biol 156:1057-1071

Sloan NA, Campbell AC (1982) Perception of food. In: Jangoux M, Lawrence JN (eds) Echinoderm nutrition. A. A. Balkema, Rotterdam, p 3-23

Smee DL, Weissburg MJ (2006a) Hard clams (Mercenaria mercenaria) evaluate predation risk using chemical signals from predators and injured conspecifics. J Chem Ecol 32:605-619

> Smee DL, Weissburg MJ (2006b) Clamming up: environmental forces diminish the perceptive ability of bivalve prey. Ecology 87:1587-1598

> Thines G, Vandenbussche E (1966) Effects of alarm substance on schooling behaviour of Rasbora heteromorpha duncker in day and night conditions. Anim Behav 14:296-302

Weissburg MJ, Ferner MC, Pisut DP, Smee DL (2002) Ecological consequences of chemically mediated prey perception. J Chem Ecol 28:1953-1970

Wisenden BD (2000) Olfactory assessment of predation risk in the aquatic environment. Philos Trans R Soc Lond B 355:1205-1208

> Zimmer RK, Butman CA (2000) Chemical signalling processes in the marine environment. Biol Bull 198:168-187

- Zimmer RK, Zimmer CA (2008) Dynamic scaling in chemical ecology. J Chem Ecol 34:822-836

Submitted: December 6, 2010; Accepted: June 10, 2011

Proofs received from author(s): August 12, 2011 